\title{
RESEARCH
}

Open Access

\section{Foot health of Aboriginal and Torres Strait Islander Peoples in regional and rural NSW, Australia}

Matthew West', Sean Sadler ${ }^{1 *}$ D, Fiona Hawke', Shannon E. Munteanu ${ }^{2,3}$ and Vivienne Chuter ${ }^{1,4}$

\begin{abstract}
Background: Foot health of Aboriginal and Torres Strait Islander Australians' has not been established. Additionally, studies have shown that there is a lack of engagement of this population with general preventive foot care services. The aim of this study was to establish foot health in Aboriginal and Torres Strait Islander people attending two recently developed, culturally safe podiatry services in rural and regional New South Wales (NSW), Australia. Secondarily the relationship between self-perceived foot health and some medical and demographic characteristics was investigated.

Methods: This descriptive cross-sectional study included participants attending the culturally safe foot health care services managed by the University of Newcastle on the Central Coast or in Wellington, both located in NSW, Australia. At the consultation, participants completed the Foot Health Status Questionnaire (FHSQ) with the assistance of an Aboriginal health care worker, underwent basic vascular and neurological screening, and podiatric treatment.
\end{abstract}

Results: A total of 111 Aboriginal and Torres Strait Islander Australians (48 from the Central Coast, and 63 from Wellington) were included. FHSQ scores for pain (75.7 \pm 26.8$)$, function (80.2 \pm 25.2$)$, footwear $(53.9 \pm 33.4)$, and general foot health $(62.0 \pm 30.9)$ were generally good, but below the optimal score of 100 . The presence of diabetes ( $n=39$ of 111 participants or $35.1 \%$ ) was associated with lower levels of self-perceived foot function $(r=-0.20$, $n=107, p=0.04)$.

Conclusion: We found that community-based foot health care services that are culturally safe are utilised by Aboriginal and Torres Strait Islander Peoples not currently at high risk of foot complications. This supports the use of culturally safe foot care services to improve engagement with preventative foot care. Future research should continue to be driven by Aboriginal and Torres Strait Islander Peoples and investigate ways to implement additional screening measures and undertake prospective evaluation of the impact of such services on health related outcomes in these communities.

Keywords: Indigenous peoples, Foot health status questionnaire, Podiatry, Cultural competency, Prevention

\footnotetext{
* Correspondence: sean.sadler@newcastle.edu.au

'Discipline of Podiatry, University of Newcastle, Ourimbah, NSW 2258,

Australia

Full list of author information is available at the end of the article
}

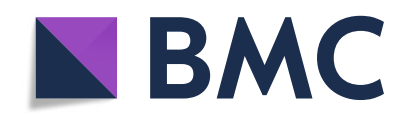

(- The Author(s). 2020 Open Access This article is licensed under a Creative Commons Attribution 4.0 International License, which permits use, sharing, adaptation, distribution and reproduction in any medium or format, as long as you give appropriate credit to the original author(s) and the source, provide a link to the Creative Commons licence, and indicate if changes were made. The images or other third party material in this article are included in the article's Creative Commons licence, unless indicated otherwise in a credit line to the material. If material is not included in the article's Creative Commons licence and your intended use is not permitted by statutory regulation or exceeds the permitted use, you will need to obtain permission directly from the copyright holder. To view a copy of this licence, visit http://creativecommons.org/licenses/by/4.0/. The Creative Commons Public Domain Dedication waiver (http://creativecommons.org/publicdomain/zero/1.0/) applies to the data made available in this article, unless otherwise stated in a credit line to the data. 


\section{Background}

Aboriginal and Torres Strait Islander Australians have a five-to-six-fold increased likelihood of developing foot complications including foot ulcer and amputation compared to non-Indigenous Australians [1-4]. Similarly, this population experiences a four-fold increase in risk of peripheral neuropathy, and are more likely to have peripheral arterial disease but less likely to have had it diagnosed [1-4]. This problem is exacerbated in rural and regional Australia where there is limited health care service availability and poor engagement with existing services $[3,5]$. Clustering of health risk factors, including disproportionately high rates of diabetes, greater risk of vascular disease, reduced socioeconomic circumstances, reduced health literacy, lack of access to culturally safe care, poor engagement with preventative health care services, and lifestyle factors including high rates of smoking and poor nutrition have been proposed to increase the risk of foot complications in this population even further [6].

Despite the documented high rates of foot complications in Aboriginal and Torres Strait Islander Peoples in tertiary healthcare settings throughout Australia, there are remarkably little data describing foot health at a community level. The available evidence indicates there is poor engagement with early intervention foot care services [3, 5]. Individuals typically seek help once a foot problem is present and often of a complex nature e.g. foot ulceration or infection, and this contributes to high rates of hospitalisation and amputation $[5,7,8]$. The lack of descriptive data relating to foot health status in this population at a community level limits our understanding of service provision needs. Additionally, the paucity of available data also limits our understanding of Aboriginal and Torres Strait Islanders' perceptions of health and illness, which may be a key driver in their health seeking behaviours. For example, previous research in an Aboriginal population in remote Arnhem Land found that community members' concepts of health related to whether they could carry out daily activities and live with their family, regardless of diagnosis of disease [9]. Therefore, the primary aim of this study was to determine the point prevalence of foot health of Aboriginal and Torres Strait Islander Australians presenting to culturally safe podiatry services in a rural and a regional community of New South Wales (NSW), Australia. Secondarily, we aimed to explore the association between demographic variables (age and sex), smoking status (never or past/current), diabetes status (present or absent) and foot health.

\section{Methods}

The University of Newcastle Human Research Ethics Committee (H-2018-0035) granted ethics approval and the Australian Health and Medical Research Council approved the project $(1376 / 18)$. Written informed consent was obtained from all participants at the start of the consultation.

\section{Participants and settings}

This descriptive cross-sectional study recruited Aboriginal and Torres Strait Islander People aged 18 years and older presenting to one of two culturally safe foot health services between March 2018 and July 2019. One of the clinics is located at Wyong hospital, which is on the Central Coast of NSW, approximately $100 \mathrm{~km}$ north of Sydney, Australia. The other clinic is located in Wellington, which is a town in inland NSW and is approximately $360 \mathrm{~km}$ North West of Sydney, Australia. Both clinics are managed by the University of Newcastle, Discipline of Podiatry and are designed to be culturally safe community clinics that are led by an Aboriginal Podiatrist, supported by Aboriginal Health Worker, and provide student placements. In being culturally safe, these clinics are designed to create an environment that is considerate of the spiritual, physical, social, and emotional world view of Aboriginal and Torres Strait Islander people, thereby creating a clinical experience which is conducive to, and supportive of, the specific needs of this community [10]. Additionally, the approach to management of patients within these clinics is one that recognises the importance of culture, family, and community for Aboriginal and Torres Strait Islander people. The services provide a mix of podiatric clinical care and health promotion with a focus on diabetes related foot complications and prevention education. The Central Coast service operates on a weekly basis from the University of Newcastle Podiatry Clinic, and the Wellington Service via an Outreach program which occurs 3 to 4 times per year in a local Aboriginal community facility. The latter service operates as a drop-in clinic without any formal appointment times.

\section{Participant characteristics}

Participant characteristics were self-reported by participants on a generic questionnaire developed by the authors for this study and included age, sex, smoking status (never or past/current), and diabetes mellitus status (present or absent).

\section{Measurement of foot health}

Following measurement of participants' characteristics, their foot health was measured through the use of a (i) patient reported outcome measure, the Foot Health Status Questionnaire (FHSQ), and (ii) clinical assessment. 


\section{Foot health status questionnaire}

Foot-specific health-related quality of life was evaluated using the FHSQ. The FHSQ is a 13-item questionnaire used to evaluate foot health across four domains (pain, function, footwear and general foot health) and can be accessed in full online via the FHSQ website [11]. Questions in each domain are scored using a 5-point Likert scale. Responses were then transformed into domain scores, that ranged from 0 (worst foot health) to 100 (best foot health). The FHSQ [11] is a valid questionnaire that has shown high retest reliability [12]. The FHSQ was not specifically designed for Aboriginal and Torres Strait Islander Peoples and may not consider how cultural differences might influence responses. To limit the potential impact of this an Aboriginal health care worker was present to assist participants if they had difficulty understanding the questions.

\section{Clinical foot assessment}

Clinical foot assessment was then conducted and involved neurological and vascular assessment of both feet and was performed by registered podiatrists with relevant clinical experience. Neurological assessment was performed via the 10-site monofilament test using a 5.07 Semmes-Weinstein monofilament [13]. An abnormal result was defined as a participant identifying less than seven out of ten sites on any foot [14]. Vascular assessment was performed via a Doppler assessment of the dorsalis pedis and posterior tibial arteries [15], using a bi-directional hand-held Doppler (Hadeco@ ES-100 V3 8 $\mathrm{mHz}$ ). An abnormal result was defined as the presence of monophasic waveforms for either artery of the left or right foot [16]. Studies have demonstrated that both monofilament [13] and Doppler waveform assessment [16] have acceptable levels of reliability.

\section{Statistical analyses}

Data were entered into Microsoft Excel and the FHSQ software (version 1.03) and then exported to the statistical package for the social sciences (SPSS) program (version 25.0 Chicago, Illinois, USA) for analysis. For continuous data, data were assessed for normality prior to inferential analysis. For descriptive analysis, means and standard deviations are reported for continuous variables, and frequency and percentages for dichotomous variables.

Correlations were performed to determine the level of association between demographic factors (age and sex), smoking status (never or past/current), and diabetes status (present or absent) for each of the FHSQ domains. The strength of the correlation was interpreted as small $(r=0.10$ to 0.29$)$, moderate $(r=0.30$ to 0.49$)$, and large $(r=0.50$ to 1.0) [17]. A standard linear regression was performed to determine the proportion of variance in each domain of the FHSQ attributed to a significantly $(p<0.05)$ correlated independent variable. Assumptions for the analyses were met.

\section{Results \\ Participants}

A total of 111 Aboriginal Australians, 48 from the Central Coast and 63 from Wellington enrolled in this study (Table 1). These figures represent approximately 0.4 and $5.6 \%$ of the total number of Aboriginal and Torres Strait Islander people living in the Central Coast and Wellington areas.

\section{Foot health assessment}

Findings from the foot health assessments are shown in Table 2. The vascular and neurological status of a number of participants is unknown because some participants chose not to have the assessments performed or only had part of the assessments conducted (Table 2).

All FHSQ domain scores were notably less than the optimum score of 100 (Table 2), with the footwear and general foot health domains being lowest. There were no statistically significant differences in FHSQ domain scores between regions. Additionally, there were no differences in rates of overt peripheral arterial disease or peripheral neuropathy between the regions (Table 2).

\section{Associations between participant characteristics and FHSQ domains}

Being female was significantly associated with lower scores on the footwear domain $(\mathrm{r}=0.29, n=110, p<$ 0.01 ). The presence of diabetes was associated with lower levels of self-perceived foot function $(\mathrm{r}=-0.20$, $n=107, p=0.04$ ) (Table 3).

\section{Regression analysis}

For the footwear domain, female sex was able to predict $9.0 \%$ of the variance in the score for this domain $\left(\mathrm{r}^{2}\right.$ $0.09, p<0.01$, beta coefficient 0.29 ). Linear regression demonstrated that the presence of diabetes predicted $4.0 \%$ of the variance in the function domain score $\left(\mathrm{r}^{2}\right.$ $0.04, p=0.04$, coefficients beta -0.20 ). No significant associations were found between the variables measured and the foot pain and general foot health domains of the FHSQ.

\section{Discussion}

The primary aim of this study was to describe the point prevalence of foot health of Aboriginal Australians presenting across two culturally safe foot health services in rural and regional NSW, Australia. We found that a high proportion of patients reported having diabetes (Central Coast $41.7 \%$, Wellington $30.1 \%$ ) and a current or past history of smoking (Central Coast 58.3\%, Wellington 
Table 1 Participant characteristics

\begin{tabular}{|c|c|c|c|}
\hline & Total group & Central Coast & Wellington \\
\hline Age, mean (SD) & $52.5(16.3)$ & $53.9(15.3)$ & $51.3(17.0)$ \\
\hline Not reported by participant, $\mathrm{n}$ (\% of total) & $10(9.0 \%)$ & $1(0.9 \%)$ & $9(8.1 \%)$ \\
\hline \multicolumn{4}{|l|}{ Sex } \\
\hline Female, n (\% of total) & $57(51.4 \%)$ & $20(41.7 \%)$ & $37(58.7 \%)$ \\
\hline Male, n (\% of total) & $53(47.7 \%)$ & $28(58.3 \%)$ & $25(39.7 \%)$ \\
\hline Not reported by participant, $\mathrm{n}$ (\% of total) & $1(0.9 \%)$ & $0(0.0 \%)$ & $1(1.6 \%)$ \\
\hline \multicolumn{4}{|l|}{ Smoking status } \\
\hline Never, n (\% of total) & $41(36.9 \%)$ & $20(41.7 \%)$ & $21(33.3 \%)$ \\
\hline Past or current, $\mathrm{n}$ (\% of total) & $57(51.4 \%)$ & $28(58.3 \%)$ & $29(46.0 \%)$ \\
\hline Not reported by participant, $\mathrm{n}$ (\% of total) & $13(11.7 \%)$ & $0(0.0 \%)$ & $13(20.7 \%)$ \\
\hline \multicolumn{4}{|l|}{ Diabetes status } \\
\hline No diabetes, $n$ (\% of total) & $68(61.3 \%)$ & $28(58.3 \%)$ & $40(63.5 \%)$ \\
\hline Diabetes, n (\% of total) & $39(35.1 \%)$ & $20(41.7 \%)$ & $19(30.1 \%)$ \\
\hline Not reported by participant, $\mathrm{n}$ ( $\%$ of total) & $4(3.6 \%)$ & $0(0.0 \%)$ & $4(6.4 \%)$ \\
\hline
\end{tabular}

46.0\%). Foot-specific health-related quality of life, evaluated using the FHSQ, was less than the optimum score of 100, with the footwear and general foot health domains being notably poorer than pain and function domains. The neurological and vascular assessments demonstrated that the rates of clinically overt peripheral arterial disease (Central Coast 4.2\%, Wellington 3.2\%) and peripheral neuropathy (Central Coast 4.2\%, Wellington 3.2\%) were low. There were not any regional differences for foot-specific health-related quality of life or overt peripheral arterial disease or peripheral neuropathy.

Capacity for comparison of the FHSQ data from this current study with previous research is challenging as there are no published data relating to foot-specific health-related quality of life in Aboriginal and Torres Strait Islander Australians. Much of the existing data investigating FHSQ domains in the general population relate to specific pathologies and the outcome of interventions, for example, treatments for plantar heel pain or foot osteoarthritis [18-21]. In the present study, mean scores for the pain, function, footwear, and general foot health domains were all higher than those previously reported in a population of older Australians using podiatry care [22]. The comparatively high FHSQ scores for our study population suggests that, on average, participants felt healthy and perceived their feet as healthy and this

Table 2 Foot health assessment

\begin{tabular}{|c|c|c|c|}
\hline Foot health measure & Total group mean \pm SD (range), $n=111$ & Central Coast mean \pm SD (range) $n=48$ & Wellington mean \pm SD (range) $n=63$ \\
\hline FHSQ, pain & $75.7 \pm 26.8(0-100)$ & $77.5 \pm 27.3(0-100)$ & $74.4 \pm 26.5(0-100)$ \\
\hline FHSQ, function & $80.2 \pm 25.2(0-100)$ & $83.1 \pm 21.1(25-100)$ & $78.0 \pm 27.9(0-100)$ \\
\hline FHSQ, footwear & $53.9 \pm 33.4(0-100)$ & $58.3 \pm 31.7(0-100)$ & $50.7 \pm 34.6(0-100)$ \\
\hline FHSQ, general foot health & $62.0 \pm 30.9(0-100)$ & $66.9 \pm 30.6(0-100)$ & $58.3 \pm 30.8(0-100)$ \\
\hline \multicolumn{4}{|l|}{ Monofilament } \\
\hline Normal $^{a}, \mathrm{n}$ (\% of total) & $63(56.8 \%)$ & $42(87.5 \%)$ & $21(33.3 \%)$ \\
\hline Abnormal $^{\mathrm{b}}, \mathrm{n}$ (\% of total) & $4(3.6 \%)$ & $2(4.2 \%)$ & $2(3.2 \%)$ \\
\hline Missing, n (\% of total) & $44(39.6 \%)$ & $4(8.3 \%)$ & $40(63.5 \%)$ \\
\hline \multicolumn{4}{|l|}{ Doppler } \\
\hline Normal $^{c}, \mathrm{n}$ (\% of total) & $60(54.1 \%)$ & $38(79.2 \%)$ & $22(34.9 \%)$ \\
\hline Abnormal $^{d,} \mathrm{n}$ (\% of total) & $4(3.6 \%)$ & $2(4.2 \%)$ & $2(3.2 \%)$ \\
\hline Missing, $\mathrm{n}$ (\% of total) & 47 (42.3\%) & $8(16.6 \%)$ & 39 (61.9\%) \\
\hline
\end{tabular}

${ }^{a}$ Defined has $\geq 7 / 10$ both feet. ${ }^{b}$ Defined has $<7$ on one foot or more. ${ }^{c}$ Defined has no monophasic waveform. ${ }^{\mathrm{d}}$ Defined has one or more monophasic waveform $/ \mathrm{s}$ 
Table 3 Pearson correlation between each FHSQ domain and participant characteristics

\begin{tabular}{lllll}
\hline & Foot Pain & Foot Function & Footwear & General foot health \\
\hline Age, $n=101$ & -0.04 & -0.17 & -0.09 & 0.10 \\
Sex, $n=110$ & 0.17 & 0.15 & $0.29^{* *}$ & -0.04 \\
Diabetes, $n=107$ & -0.18 & $-0.20^{*}$ & -0.15 & -0.01 \\
Location, $n=111$ & -0.06 & -0.10 & -0.11 & -0.14 \\
Smoking, $n=98$ & -0.003 & -0.05 & 0.17 & -0.10 \\
${ }^{*} p<0.05,{ }^{* *} p<0.01$ & & & &
\end{tabular}

was consistent with our low rates of abnormal vascular and neurological findings.

Existing data relating to foot heath in Aboriginal Australians indicates high rates of disease, including peripheral vascular disease and neuropathy, with many of the studies derived from outcomes from public hospital admissions and high risk foot centres [3, 4, 23]. Importantly the findings of this present study should not be considered contradictory to previous research. The high rates and devastating outcomes of foot disease for Aboriginal and Torres Strait Islander Australians are unequivocal $[2,4,24,25]$. Our research outcomes most likely reflect recruitment from a community-based population and offer insight into the potential effectiveness of providing community-led, culturally safe health care to reduce morbidity and mortality through early intervention, and of the critical role of accessible prevention and management services.

Lack of engagement of Aboriginal and Torres Strait Islander Peoples with existing preventative foot care services, for example those with diabetes, is common $[5,8]$ and needs to be improved to successfully reduce foot disease and complications such as amputations [26]. A number of barriers to Indigenous populations accessing preventative care have been identified, including poor relationships with health care providers, health care providers' lack of acceptance of the role of family in care provision, and poor community engagement with available services [9, 27-29]. In addition, fatalist beliefs towards one's own health (i.e. that ill-health is unavoidable) and towards Western health service provision (i.e. that accessing health care is only for the very sick and has negative outcomes) has been documented in Australian Aboriginal and Torres Strait Islander Peoples [9]. This belief system has been linked to historical and current issues of dispossession and socioeconomic inequality, concern over being removed from family and community for treatment, along with lack of improvement in Aboriginal and Torres Strait Islander health outcomes through a Western model of health care delivery. The results of the current study, showing that footspecific health-related quality of life in the sample was, on average, generally good, with low rates of peripheral arterial disease and neuropathy, provide evidence to refute a fatalistic approach to foot ill-health.

Access to culturally safe health services using Aboriginal health workers provided in spaces that have significance (e.g. cultural or physical) to the local community has been shown to increase utilisation of health care [30-32]. Although a number of initiatives have been developed to provide culturally safe foot care, there has been little evaluation of their effectiveness [7]. Our findings support the use of culturally safe service provision within the community to encourage engagement with and early uptake of preventative care in those with chronic disease. However, further research is needed to broaden the understanding of the fundamental foot health care needs of Aboriginal and Torres Strait Islander Peoples, and to establish effective strategies for preventing foot related complications of chronic disease. Importantly, this must be driven by Aboriginal and Torres Strait Islander Peoples so that the services are not only culturally appropriate and safe, but to help encourage and empower other community members to seek out and engage with health care services in the future.

\section{Limitations}

A number of limitations should be considered when interpreting our findings. We only measured a small number of variables related to participant demographics, diagnosed conditions (only diabetes), and vascular and neurological function. Additional data related to participants' physical characteristics (e.g. height, weight, and waist circumference), diagnosed conditions (e.g. duration, complications, and disease specific levels of severity such as HbA1c), and additional vascular (e.g. toe and ankle brachial indices) and neurological (e.g. graduated tuning fork) assessments would provide further insight into Aboriginal and Torres Strait Islander Peoples' lower limb health. Furthermore, the FHSQ has not been validated in Aboriginal and Torres Strait Islander communities and, although administered with the help of an Aboriginal Health Worker, is a Western mechanism to quantify foot-specific health-related quality of life. Further investigation of Aboriginal and Torres Strait Islander perceptions of foot health and what good health 
entails is required to continue to develop effective foot complication prevention programs. Finally, the vascular or neurological status of the number of participants (40\%) who chose not to have assessments performed or for whom assessments were incomplete or were not the participant's priority is unknown. Although a limitation of the research, this approach was integral to the overarching priority of the clinical services to, first and foremost, develop community trust and engagement. Caution is recommended when attempting to generalise the findings from this study to other Aboriginal and Torres Strait Islander communities, especially those in remote locations, because of potential differences in a number of variables measured and the culturally diverse nature, kinship, and beliefs of these people across all First Nations.

\section{Conclusions}

We found that Aboriginal Australians presenting to recently developed and culturally appropriate podiatry services have relatively high levels of foot health. This suggests that these services provide a unique early opportunity for podiatrists to identify, manage, and implement preventative health care, to minimise the burden of foot complications in this population. Future research should further explore foot health from the perspective of Aboriginal and Torres Strait Islander Peoples and prospectively evaluate the impact of culturally safe foot health services on health outcomes in these communities.

\section{Abbreviations}

NSW: New South Wales; FHSQ: Foot Health Status Questionnaire;

SPSS: Statistical package for social sciences; SD: Standard deviation

\section{Acknowledgements}

We would like to acknowledge and thank the Darkinjung and Wiradjuri people of the Central Coast and Wellington regions of NSW for their support of, and invaluable contribution to, this research.

\section{Authors' contributions}

MW, SEM, FH, and VC were involved in designing the study. MW and VC were involved in collecting the data and interpreting the results. SS and VC were involved in data entry and analysis, and interpreting the results. SS, MW, VC drafted the manuscript. The authors read and approved the final manuscript.

\section{Funding}

Lowitja Institute, Woodend Foundation: Perpetual Philanthropy.

\section{Availability of data and materials}

Requests for further detail on the data collected in this study, or data sharing arrangements, can be submitted to Vivienne Chuter (Vivienne. chuter@newcastle.edu.au).

\section{Ethics approval and consent to participate}

The Human Research Ethics Committee at the University of Newcastle $(\mathrm{H}$ 2018-0035) approved the study. Written informed consent was obtained from all participants prior to their participation.

\section{Consent for publication}

Not applicable.

\section{Competing interests}

The authors declare that they have no competing interests.

\section{Author details}

${ }^{1}$ Discipline of Podiatry, University of Newcastle, Ourimbah, NSW 2258, Australia. ${ }^{2}$ Discipline of Podiatry, School of Allied Health, Human Services and Sport, La Trobe University, Melbourne, Victoria 3086, Australia. ${ }^{3}$ La Trobe Sport and Exercise Medicine Research Centre, School of Allied Health, Human Services and Sport, La Trobe University, Melbourne, Victoria 3086, Australia. ${ }^{4}$ Priority Research Centre for Physical Activity and Nutrition, University of Newcastle, Newcastle, NSW 2308, Australia.

Received: 10 March 2020 Accepted: 19 May 2020

Published online: 28 May 2020

\section{References}

1. West M, Chuter V, Munteanu S, Hawke F. Defining the gap: a systematic review of the difference in rates of diabetes-related foot complications in aboriginal and Torres Strait islander Australians and non-indigenous Australians. J Foot Ankle Res. 2017:10(1):48.

2. Ewald D, Patel M, Hall G. Hospital separations indicate increasing need for prevention of diabetic foot complications in Central Australia. Aust J Rural Health. 2001;9(6):275-9.

3. O'Rourke S, Steffen C, Raulli A, Tulip F. Diabetic major amputation in far North Queensland 1998-2008: what is the gap for indigenous patients? Aust J Rural Health. 2013;21(5):268-73.

4. Steffen C, O'Rourke S. Surgical Management of Diabetic Foot Complications: the far North Queensland profile. Aust N Z J Surg. 1998;68(4):258-60.

5. West M, Chuter V, Follent D, Hawke F. Utilisation of public podiatry and diabetes services by the aboriginal and Torres Strait islander community of the central coast of NSW. Aust Indigenous Health Bull. 2016;16(4).

6. Australian Institute of Health and Welfare. The health and welfare of Australia's aboriginal and Torres Strait islander peoples. Canberra: AlHW; 2015. Cat. no. IHW 147.

7. Chuter V, West M, Hawke F, Searle A. Where do we stand? The availability and efficacy of diabetes related foot health programs for aboriginal and Torres Strait islander Australians: a systematic review. J Foot Ankle Res. 2019; 12(1):17.

8. Norman PE, Schoen DE, Gurr JM, Kolybaba ML. High rates of amputation among indigenous people in Western Australia. Med J Aust. 2010;192(7):421.

9. Senior K, Chenhall R. Health beliefs and behavior: the practicalities of "looking after yourself" in an Australian aboriginal community. Med Anthropol Q. 2013;27(2):155-74.

10. Williams R. Cultural safety--what does it mean for our work practice? Aust N Z J Public Health. 1999:23(2):213-4.

11. Bennett PJ, Patterson C, Wearing S, Baglioni T. Development and validation of a questionnaire designed to measure foot-health status. J Am Podiatr Med Assoc. 1998;88(9):419-28.

12. Riskowski JL, Hagedorn TJ, Hannan MT. Measures of foot function, foot health, and foot pain: American Academy of orthopedic surgeons lower limb outcomes assessment: foot and ankle module (AAOS-FAM), Bristol foot score (BFS), revised foot function index (FFI-R), foot health status questionnaire (FHSQ), Manchester foot pain and disability index (MFPDI), podiatric health questionnaire $(\mathrm{PHQ})$, and rowan foot pain assessment (ROFPAQ). Arthritis Care Res. 2011;63(S11):S229-S39.

13. Lanting SM, Spink MJ, Tehan PE, Vickers S, Casey SL, Chuter VH. Noninvasive assessment of vibration perception and protective sensation in people with diabetes mellitus: inter- and intra-rater reliability. J Foot Ankle Res. 2020;13(1):3.

14. Lee S, Kim H, Choi S, Park Y, Kim Y, Cho B. Clinical usefulness of the two-site Semmes-Weinstein monofilament test for detecting diabetic peripheral neuropathy. J Korean Med Sci. 2003;18(1):103-7.

15. Tehan PE, Chuter VH. Use of hand-held Doppler ultrasound examination by podiatrists: a reliability study. J Foot Ankle Res. 2015;8(1):36.

16. Tehan PE, Sebastian M, Barwick AL, Chuter VH. How sensitive and specific is continuous-wave Doppler for detecting peripheral arterial disease in people with and without diabetes? A cross-sectional study. Diab Vasc Dis Res. 2018; 15(5):396-401.

17. Cohen J. Statistical power analysis for the behavioral sciences. Hillsdale: L. Erlbaum Associates; 1988. 
18. Cotchett MP, Munteanu SE, Landorf KB. Effectiveness of trigger point dry needling for plantar heel pain: a randomized controlled trial. Phys Ther. 2014;94(8):1083-94.

19. Landorf KB, Radford JA, Hudson S. Minimal important difference (MID) of two commonly used outcome measures for foot problems. J Foot Ankle Res. 2010;3:7.

20. Menz HB, Auhl M, Tan JM, Levinger P, Roddy E, Munteanu SE. Effectiveness of foot orthoses versus rocker-sole footwear for first metatarsophalangeal joint osteoarthritis: randomized trial. Arthritis Care Res. 2016;68(5):581-9.

21. Munteanu SE, Zammit GV, Menz HB, Landorf KB, Handley CJ, Elzarka A, et al. Effectiveness of intra-articular hyaluronan (Synvisc, hylan G-F 20) for the treatment of first metatarsophalangeal joint osteoarthritis: a randomised placebo-controlled trial. Ann Rheum Dis. 2011;70(10):1838-41.

22. Menz HB, Auhl M, Ristevski S, Frescos N, Munteanu SE. Comparison of the responsiveness of the foot health status questionnaire and the Manchester foot pain and disability index in older people. Health Qual Life Outcomes. 2014;12(1):158.

23. Commons RJ, Robinson CH, Gawler D, Davis JS, Price RN. High burden of diabetic foot infections in the top end of Australia: an emerging health crisis (DEFINE study). Diabetes Res Clin Pract. 2015;110(2):147-57.

24. Azzopardi P, Brown AD, Zimmet P, Fahy RE, Dent GA, Kelly MJ, et al. Type 2 diabetes in young indigenous Australians in rural and remote areas: diagnosis, screening, management and prevention. Med J Aust. 2012;197(1):32-6.

25. Maple-Brown L, Cunningham J, Dunne K, Whitbread C, Howard D, Weeramanthri T, et al. Complications of diabetes in urban indigenous Australians: the DRUID study. Diabetes Res Clin Pract. 2008;80(3):455-62.

26. Boulton AJM, Vileikyte L, Ragnarson-Tennvall G, Apelqvist J. The global burden of diabetic foot disease. Lancet. 2005;366(9498):1719-24

27. Brannelly $\mathrm{T}$, Boulton A, te Hiini A. A relationship between the ethics of care and Măori worldview - the place of Relationality and care in Maori mental health service provision. Ethics Social Welfare. 2013;7(4):410-22.

28. Conway J, Tsourtos G, Lawn S. The barriers and facilitators that indigenous health workers experience in their workplace and communities in providing self-management support: a multiple case study. BMC Health Serv Res. 2017;17(1):319

29. Thiede M, Akweongo P, McIntyre D. Exploring the dimensions of access. In: McIntyre D, Mooney G, editors. The economics of health equity. Cambridge: Cambridge University Press; 2007. p. 103-23.

30. Cooper J, Moore S, Palmer L, Reinhardt J, Roberts M, Solomon A, et al. Partnership approach to indigenous primary health care and diabetes: a case study from regional New South Wales. Aust J Rural Health. 2007;15(1):67-70

31. Durey A, McEvoy S, Swift-Otero V, Taylor K, Katzenellenbogen J, Bessarab D. Improving healthcare for aboriginal Australians through effective engagement between community and health services. BMC Health Serv Res. 2016;16:224.

32. McDermott RA, Schmidt B, Preece C, Owens V, Taylor S, Li M, et al. Community health workers improve diabetes care in remote Australian indigenous communities: results of a pragmatic cluster randomized controlled trial. BMC Health Serv Res. 2015;15(1):68.

\section{Publisher's Note}

Springer Nature remains neutral with regard to jurisdictional claims in published maps and institutional affiliations.

Ready to submit your research? Choose BMC and benefit from:

- fast, convenient online submission

- thorough peer review by experienced researchers in your field

- rapid publication on acceptance

- support for research data, including large and complex data types

- gold Open Access which fosters wider collaboration and increased citations

- maximum visibility for your research: over $100 \mathrm{M}$ website views per year

At BMC, research is always in progress.

Learn more biomedcentral.com/submissions 